\title{
Isolate and irreducible radial head dislocation in children: a rare case of capsular interposition
}

\author{
Luigi Tarallo* ${ }^{*}$, Michele Novi, Giuseppe Porcellini and Fabio Catani
}

\begin{abstract}
Background: Radial head dislocation with no associated lesions, is a relatively uncommon injury in children. In this case report, it is reported a case of anteromedial locked radial head dislocation in children, and we discuss its clinical presentation and pathogenetic mechanism of injury.

Case presentation: An 8-year-old girl fell off on her right forearm with her right elbow extended in hyperpronation. An isolated radio-capitellar dislocation was identified with no other fractures or neurovascular injuries associated. Elbow presented an extension-flexion arc limited $\left(0^{\circ}-90^{\circ}\right)$, and the prono-supination during general anesthesia shows "a sling effect" from maximal pronation $\left(+55^{\circ}\right)$ and supination $\left(+90^{\circ}\right)$ to neutral position of forearm. The radial head dislocation was impossible to reduce and an open reduction was performed using lateral Kocher approach. The radial head was found "button-holed" through the anterior capsule. The lateral soft tissues were severely disrupted and the annular ligament was not identifiable. Only by cutting the lateral bundle of the capsule was possible to reduce the joint. At 50 moths follow-up, patient presented a complete Range of motion (ROM), complete functionality and no discomfort or instability even during sport activities.

Discussion and conclusion: It is important to understand the pathogenic mechanisms of locked radial head dislocation in children. Some mechanism described are the distal biceps tendon or the brachialis tendon interposition. However even the anterior capsule can hinder reduction. A characteristic "sling-effect" of the forearm could be pathognomonic for capsular button-holing. Surgical release of the capsular bundle sometimes is the only way to reduce the dislocation and obtain a good outcome.
\end{abstract}

Keywords: Locked radial head dislocation, Children elbow dislocation, Capsular button-holed

\section{Background}

Radial head dislocation rarely occurs in patients younger than 8 years old, (peak incidence of elbow dislocation is 12-13 years of age) and it is often associated with ulna fracture such as a Monteggia injury or plastic deformation injuries described as Monteggia-variant [1, 2]. The radial head subluxation ("pulled elbow" or "nursemaid elbow") however is a common traumatic condition in pediatric

\footnotetext{
* Correspondence: luigi.tarallo@unimore.it
}

Orthopedics and Traumatology Department, University of Modena and Reggio Emilia, Policlinico di Modena, Modena Via del Pozzo 71, 41124 Modena, Italy population, that mainly occurs in children between 1 and 4 years of age and it can generally be reduced with forced flexion of the elbow associated with full supination. If the anterolateral radial head dislocation is common, on the other hand a true radio-capitellar dislocation is a relatively uncommon injury in children. Often, anterior radiocapitellar dislocations may occur as the result of combined axial, torsional, and/or extension forces, and associated injury such as fracture, ulno-humeral dislocation, and ligamentous disruption [3]. Usually the commonly noted block to anatomic reduction of radial head dislocation is an interposed annular ligament which, if damaged, should

(c) The Author(s). 2020 Open Access This article is licensed under a Creative Commons Attribution 4.0 International License, which permits use, sharing, adaptation, distribution and reproduction in any medium or format, as long as you give appropriate credit to the original author(s) and the source, provide a link to the Creative Commons licence, and indicate if changes were made. The images or other third party material in this article are included in the article's Creative Commons licence, unless indicated otherwise in a credit line to the material. If material is not included in the article's Creative Commons licence and your intended use is not permitted by statutory regulation or exceeds the permitted use, you will need to obtain permission directly from the copyright holder. To view a copy of this licence, visit http://creativecommons.org/licenses/by/4.0/ The Creative Commons Public Domain Dedication waiver (http://creativecommons.org/publicdomain/zero/1.0/) applies to the data made available in this article, unless otherwise stated in a credit line to the data. 
be repaired to maintain stable joint congruency following reduction $[4,5]$. In this case report, we present a case of anteromedial radial head dislocation in children, and discuss its clinical presentation and pathogenetic mechanism of injury.

\section{Case presentation}

An 8-year-old girl fell off a table, landed on the ground, and twisted her right forearm with her right elbow extended in hyperpronation. Clinical presentation of the elbow was swelling, pain and a severe functional limitation, but there were no signs of neurologic or vascular injury. X-ray, and a CT scan was carried out to identify any associated fractures. An isolated radio-capitellar dislocation was identified at the emergency room where an unsuccessful closed reduction attempt was carried out (Fig. 1a-b). The day after the trauma, on examination under anesthesia, forearm rotation and flexion-extension were examined (Fig. 2). The patient presented a limited extension-flexion arc of motion $\left(0^{\circ}-90^{\circ}\right)$ and the prono-supination during general anesthesia showed "a sling effect" with an elastic return from maximal pronation $\left(+55^{\circ}\right)$ and maximal supination $\left(+90^{\circ}\right)$ to neutral position of forearm (Fig. 3 and video attached in supplementary contents). The radial head dislocation was impossible to reduce with the elbow fully flexed and supinated; no elbow instability to varus or valgus stress was assessed under fluoroscopic examination. After attempting an unsuccessful closed reduction of the radial head subluxation under general anesthesia, an open reduction was carried out using postero-lateral Kocher approach. The surgical exposure of the joint using Kocher approach, revealed an anterior dislocation of the radial head button-holed through the anterior capsule (Fig. 4a). The lateral soft tissues were severely disrupted and the annular ligament was not identifiable. The radial head was dislocated anteriorly, with elbow in extension and pushed anteromedial by the lateral border of the joint capsule (Fig. 4b). Only by cutting a bundle of the capsule without violating the annular and collateral ligament was it possible to reduce the radial head in the anatomical position, with accurate blunt dissection the radial nerve was identified (Fig. 4c) and a complete flexion-extension arc of motion was obtained; $80^{\circ}$ of pronation and $85^{\circ}$ of supination have been reached. The elbow was stable throughout the entire range of movement. The patient's arm was set in a plaster cast and immobilized in $90^{\circ}$ of flexion for 3 weeks. Postoperatively, radiographs demonstrated anatomic radio-capitellar alignment. Six months post-injury, her right elbow showed a complete (ROM), no residual instability

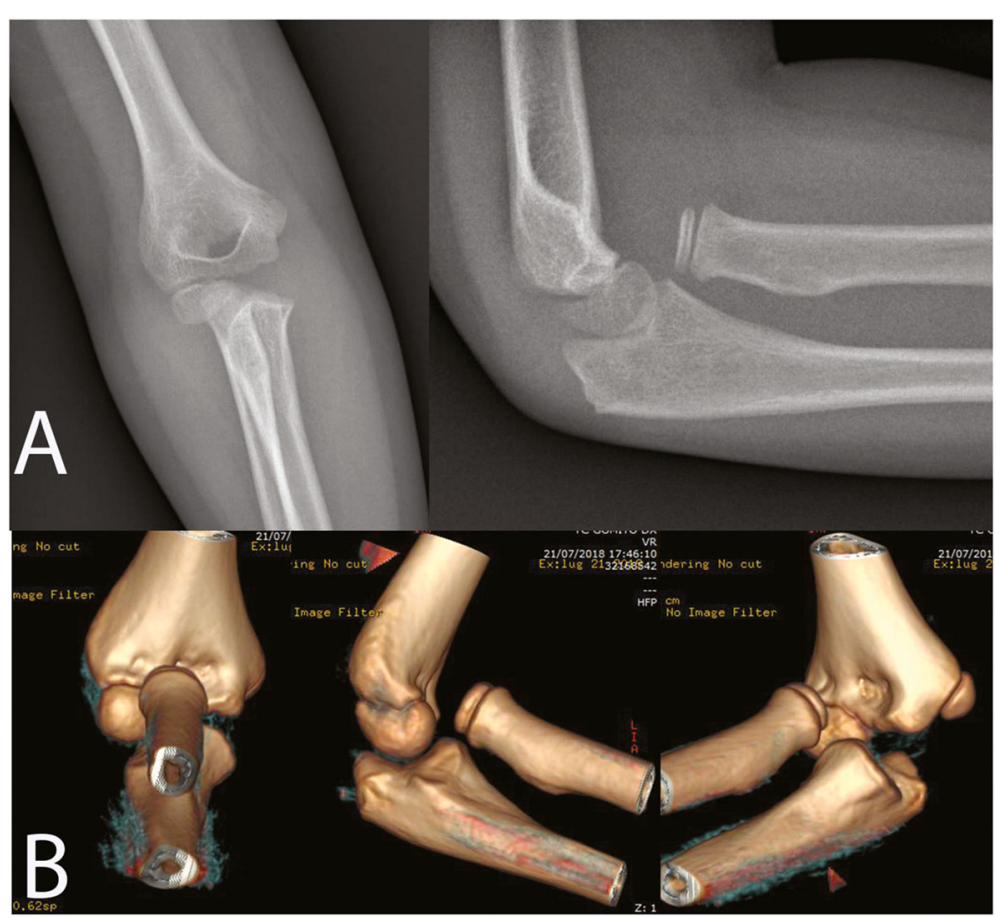

Fig. 1 X-ray (a) and CT scan (b) of radial head dislocation 


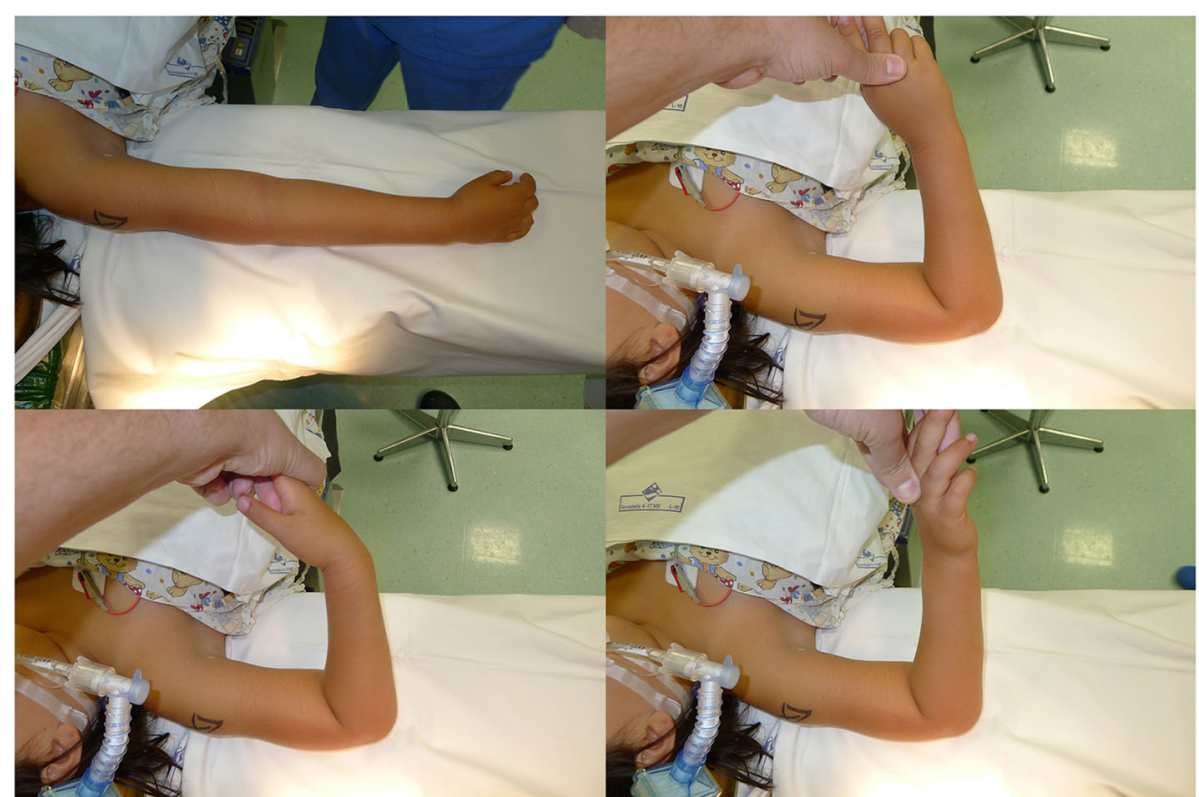

Fig. 2 Pre-Operative clinical examination

and the X-rays also showed an anatomical congruence of radio-capitellar joint.

At 50 moths followup, patient presented a complete ROM, complete functionality and no discomfort during sport activities.

\section{Discussion and conclusion}

Traumatic radial head dislocation is usually associated with fractures of the forearm [6, 7]. Isolated radial

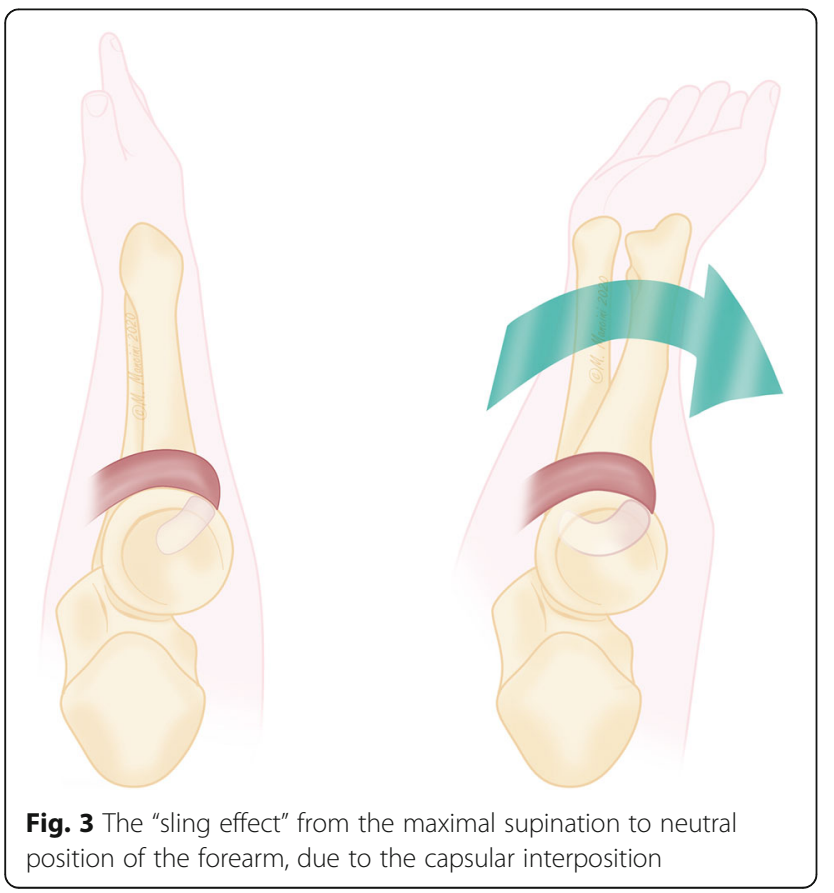

head dislocation in children is rare and most of this injury represent a monteggia-variant lesion, with plastic deformation of the ulna. In most cases of acute traumatic radial head dislocation, closed reduction is easily accomplished. Failure of closed reduction is often due to soft tissue interposition with either the annular ligament or joint capsule [8]. C. Camp and O'Driscoll, described a buttonholing of the radial head in the brachialis as a cause for irreducible dislocation including an anterior and medially dislocated radial head in absence of identifiable intra-articular block of joint reduction [3]. This pathogenetic mechanism described by Camp in the anatomic dissection, shows an elbow in flexion of $90^{\circ}$ and cannot clarify the complete extension of the elbow allowed in our case. Furthermore, an extension of the elbow could lead to disengage the radial head from the lateral portion of brachial tendon during the extension maneuver (Fig. 5) [9]. In our case the radial head seems locked in a sort of buttonholing on the anterior capsule and pushed medially with respect to the anatomical position. The clinical presentation of the patient showed an arc of movement of complete extension and limited flexion to $90^{\circ}$, associated with an elastic return to neutral position either from maximal pronation and maximal supination, that we described as a "sling effect". If a loop of the biceps tendon around the radial neck was present, as described by Vidyadhar V. Upasani [10], it can only explain this elastic return when the forearm pass from supination to neutral position like a sort of "spring preloading" but not in the opposite side from maximal pronation to neutral position because the 

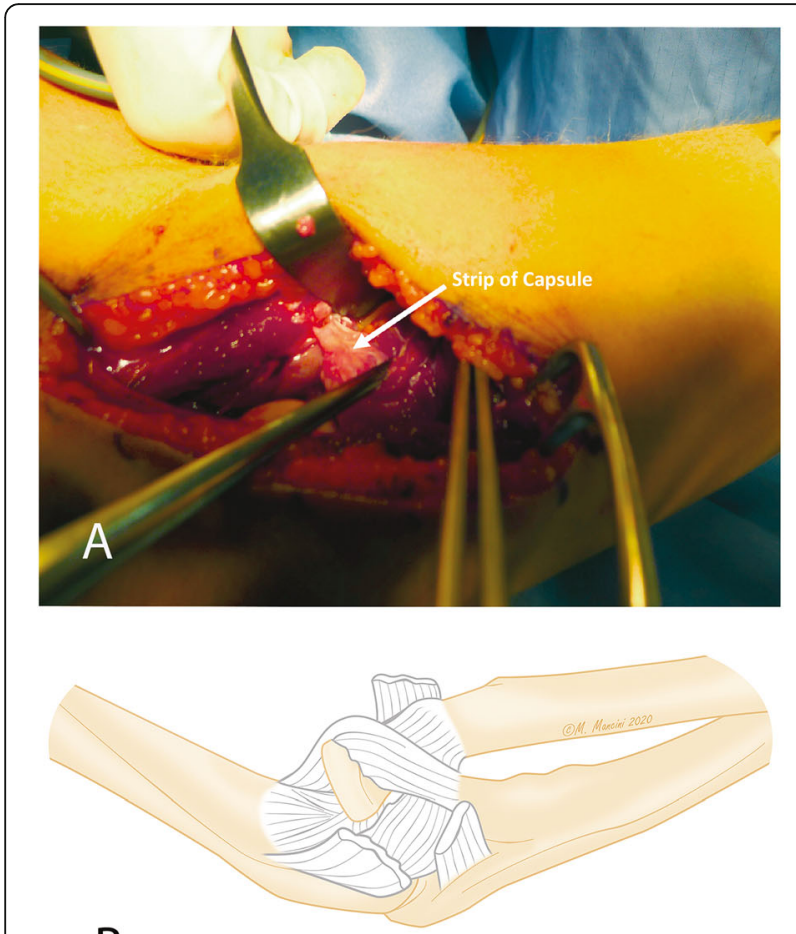

B

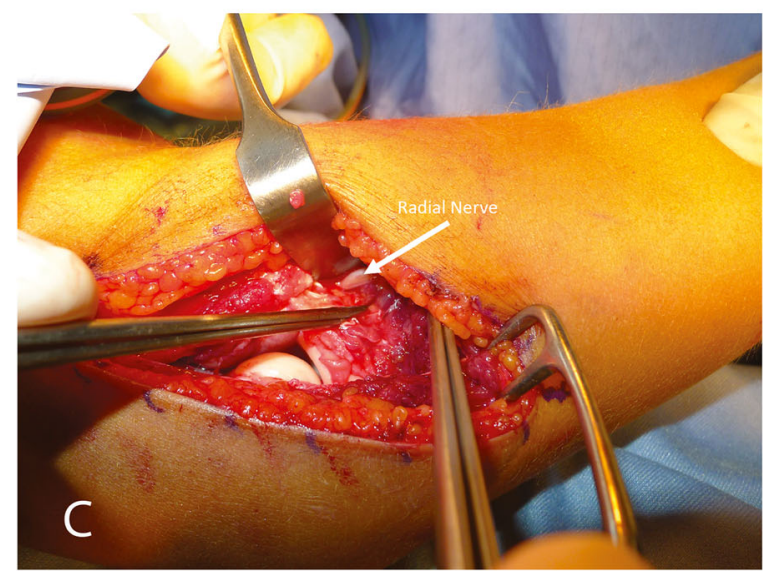

Fig. 4 Radial head dislocation with button-holing of the capsule (a); Pathogenic mechanism illustration (b); Reduction of the dislocation and radial nerve identification (c)

tendon is released. In our case we found this slingeffect both in supination and pronation.

In our case, we described a mechanism very similar to brachialis tendon interposition described by Camp, in fact the CT scan images are very similar, but we found a strip of the capsule which locked the radial head in the volar and medial position without any possibility of reducing the dislocation of radial head. All attempts to reduce the radial head dislocation during surgery were superfluous.

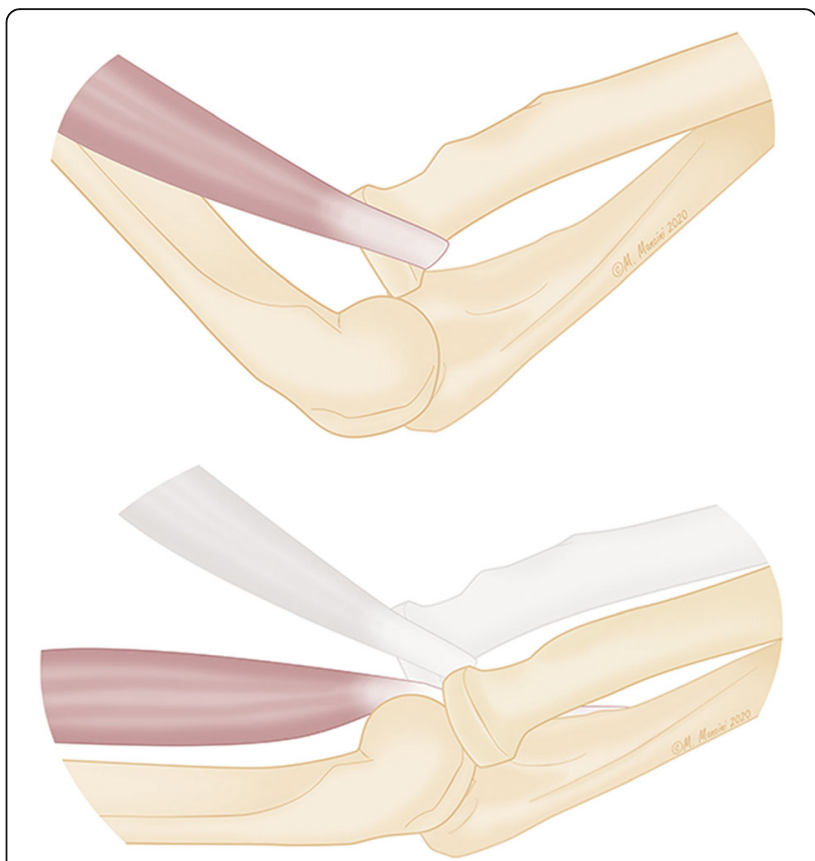

Fig. 5 Mechanism of disengagement of the radial head from the brachial tendon

The capsule, interposed between the radial head and the capitellum, blocked reduction of the radial head and had to be incised to restore joint alignment. In conclusion we suggest considering the buttonholing of the radial head incarcerated on the volar capsule in presence of irreducibility of the radial head, if the patient presents an arc of movement of $0-90^{\circ}$, a supination relatively complete $90^{\circ}$ and a limited pronation. Another interesting sign is the clinical presentation of the forearm that passes from complete supination to neutral position in a sort of "sling" as well as from maximal pronation to neutral position.

\section{Supplementary information}

Supplementary information accompanies this paper at https://doi.org/10. 1186/s12891-020-03685-5.

\section{Additional file 1 .}

\section{Abbreviation}

ROM: Range of motion

\section{Acknowledgements}

Not applicable.

\section{Authors' contributions}

LT designed the study. MN and LT was responsible for data collection and wrote the draft. GP and FC contributed to interpretation of data. All authors critically revised the manuscript. All authors read and approved the manuscript.

\section{Funding}

Authors declare that they didn't receive any support or commitment, or agreement to provide such benefits in connection with this study. 


\section{Availability of data and materials}

Data that support the findings of the study are available from the corresponding author on reasonable request.

\section{Ethics approval and consent to participate}

The patient gave informed consent prior to being included in this study performed in accordance with the Ethical Standards of the 1964 Declaration of Helsinki as revised in 2000.

\section{Consent for publication}

Written informed consent was obtained from the patient's parent for publication of this case report and any accompanying images.

\section{Competing interests}

Luigi Tarallo is a member of Editorial Board of BMC Musculoskeletal disorder.

The other authors declare that they have no competing interests.

Received: 29 April 2020 Accepted: 29 September 2020

Published online: 07 October 2020

\section{References}

1. Lins RE, Simovitch RW, Waters PM. Pediatric elbow trauma. Orthop Clin North Am. 1999;30:119-32.

2. Bado JL. The Monteggia lesion. Clin Orthop Relat Res. 1967;50:71-86 PMID: 6029027.

3. Camp CL, O'Driscoll SW. Transbrachialis Buttonholing of the Radial Head as a Cause for Irreducible Radiocapitellar Dislocation: A Case Report. J Pediatr Orthop. 2015;35(7):e67-71.

4. Choung W, Heinrich SD. Acute annular ligament interposition into the radiocapitellar joint in children (nursemaid's elbow). J Pediatr Orthop. 1995; 15:454-6.

5. Corella F, Horna L, Villa A, et al. Irreducible 'pulled elbow' report of two cases and review of the literature. J Pediatr Orthop Part B. 2010:19:304-6.

6. Watanabe K, Iwabu S, Hosoya T. Traumatic isolated anterior dislocation of the radial head in an adult: a casereport. J Shoulder Elb Surg. 2005;14:554-6. https://doi.org/10.1016/j.jse.2004.08.005.

7. Yoshihara Y, Shiraishi K, Imamura K. Irreducible anteromedial dislocation of the radial head caused by biceps tendon clinging around the radial neck. J Trauma. 2002:53:984-6.

8. Neviaser RJ, LeFevre GW. Irreducible isolated dislocation of the radial head a case report. Clin Orthop Relat Res. 1971;80:72-4 PMID: 5133333.

9. Cates RA, Steinmann SP, Adams JE. Irreducible anteromedial radial head dislocation caused by the brachialis tendon: a case report. J Soulder Elbow Surg. 2016;25(8):Pe232-5.

10. Upasani W, Hentzen ER, Meunier MJ, Abrams RA. Anteromedial radial head fracture-dislocation associated with a transposed biceps tendon: a case report. J Shoulder Elb Surg. 2011;20(4):e14-8. https://doi.org/10.1016/j.jse 2010.11.025 Epub 2010 Dec 31.

\section{Publisher's Note}

Springer Nature remains neutral with regard to jurisdictional claims in published maps and institutional affiliations.

Ready to submit your research? Choose BMC and benefit from:

- fast, convenient online submission

- thorough peer review by experienced researchers in your field

- rapid publication on acceptance

- support for research data, including large and complex data types

- gold Open Access which fosters wider collaboration and increased citations

- maximum visibility for your research: over $100 \mathrm{M}$ website views per year

At BMC, research is always in progress.

Learn more biomedcentral.com/submissions 